\title{
REFLECTIONS ON THE ROLE OF ECONOMIC AND FINANCIAL MANAGEMENT
}

\author{
Marius MILANDRU \\ mnmilandru@yahoo.com
}

“NICOLAE BĂLCESCU” LAND FORCES ACADEMY, SIBIU, ROMANIA

\begin{abstract}
The aim of this article is not merely to present economic and financial management but that of discovering and analyzing ways, in which its roles, as inseparable instruments of the micro- and microeconomic system, are defined, applied and rendered necessary within organizations. There are many ways to define economic and financial management, depending on the various approaches of authors, specialists or practitioners. At the same time, its roles sum up the essence of economic and financial processes. In fact, their implementation stands for what economic and financial management represents both as art and as science. Exercising the roles of economic and financial management correctly and efficiently is a prerequisite of the economic success of an organization. Failing to create or apply any of these roles, however insignificant its place might seem within the organization, would surely entail risks, vulnerability, and even failure.
\end{abstract}

\section{KEYWORDS:}

Economic and financial management; the roles of economic and financial management; principles, techniques, management tools; economic and financial risks and vulnerabilities.

\section{Introduction}

The transition from a planned and centralized economy to one based on market conditions has imposed fast and significant changes in all domains, be that social, political, economic, organizational, judicial, etc. They have integrated necessary measures to diminish guvernmental intervention on a microeconomic level and to replace administrative levers with economic ones.

Thus, methods of leadership stemming from an excesive centralism have been eliminated and replaced by methods of economic management that correspond to the new socio-economic context.
It is a unanimously accepted fact that management science needs to offer suitable theoretical and practical solutions to eveything that is included under the umbrella of management of organizationspecific activities at both micro- and macroeconomic levels.

The term "management" refers to "the process of efficient and effective objective fulfillment with and through other people" (Robbins \& Coulter, 2007, p. 6).

Management has been defined in various ways by different specialists so much so that today we know over 100 definitions of it. 
In this context, the financial and economic management must be considered as a component of the general management of organizations with an objective to sustain the production of funds necessary to complete organizational activities, to ensure the efficiency of capital use and to establish, this way, the economic and financial support necessary to sustain market performance for the organization.

In other words, it is necessary to employ the attributes of economic and financial management correctly and efficiently. Neglecting any of its roles, however insignificant its place may seem, renders it vulnerable and destined to fail, which would obviously bring about serious and undesirable consequences for the organization.

This role represents the sum of principles, methods, tools and objectives which are specific of the organization, aiming to identify ways to create and use financial and economic resourses.

Based on the above mentioned aspects we can state some objectives of the economic and financial management:

- economic and financial evaluation of the effort that is to be invested into the undertaken actions within a particular period of time;

- providing capital, at the right time and the appropriate quality standards and structure dictated by necessities, at the lowest possible cost;

- monitoring the way capital is used and decision factors from other cetres of responsibility are influenced, with an aim to efficiently employ the funds drawn into the circuit;

- assuring and maintaining the short term and long term economic and financial balance corresponding with the needs of the organization;

- pursuing the expected financial and economic results and distributing them towards the aimed destination.

The contribution of economic and financial management to the achievements of the organization is essential, in many cases decisive, since financing equals decision-making.

Consequently, it is necessary to increase the role of economic and financial management and, implicitly, that of specialists in the financial field in conducting activities within the organization and consolidating decisions pertaining to the allocation of funds.

2. Definition of the roles of economic and financial management

The roles of economic and financial management are the type of activities that differenciate managers from executive personnel, specific for every organization, both generally and specifically, within departments, depending on the hierarchical position of the manager.

The roles of economic and financial management as extension and completion to the roles of general management are the following:

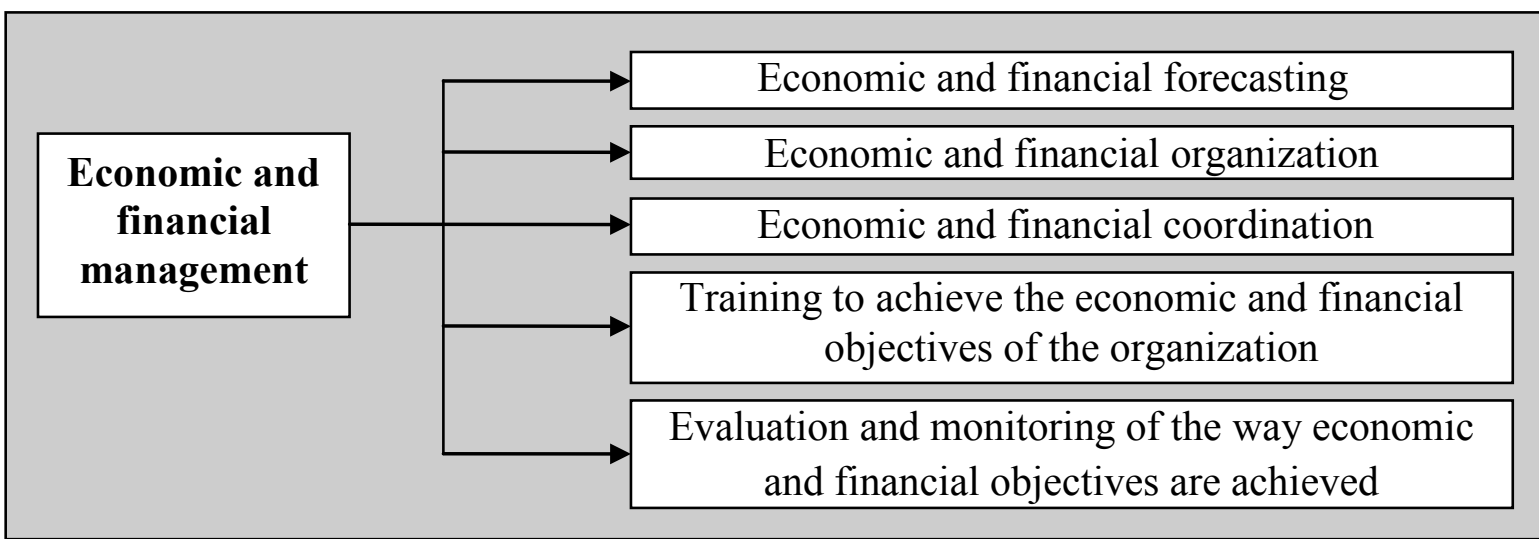




\section{Economic and financial forecasting}

"The role of forecasting is defined by the collective of workprocesses through which the main objectives of the companycommercial company, autonomous administration or public institutionand its components - as well as the main means and resources for their acheievement are determined" (Niculescu \& Verboncu, 1999, p. 43).

Economic and financial forecasting, the first and most important role of the management process is a component of the general forecasting of organizations, complementing and puting into practice their economic and financial policies.

Forecasting in the economic and financial management of organizations is constituted by the actions undertaken by top management in view of establishing strategical and tactical objectives for the organization, identifying economic and financial resources and the materials necessary to obtain them.

For an organization to develop and impose itself, daring but also realistic objectives are necessary, whith affordable economic and financial resources available for their achievement. In this respect, economic and financial forecasting and policy must play an active role in establishing and achieving strategic economic objectives for the organization as a whole.

The assumption of this extremely important role requires for the management of the organization to "translate" any strategic objective, any tactical decision in income and expenses, in profit and payment. Without this quantification those objectives and decisions, the economic policies, the whole strategy of the organization is unfounded.

Economic and financial planning as a forecasting activity is vital for the organization and its management, with the quality of being both rigorous and flexible and also adaptable to the reactions of the market.
Economic and financial forecasting in public institutions is an extremely complex and laborious activity that includes the following activities and instruments:

- economic and financial forecasting;

- economic and financial policies;

- economic and financial strategies;

- economic and financial plans;

- budgets for income and expenses.

Economic and financial forecasting can contribute to a great extent to the general forecasting activity of the public institution, especially in the following stages:

- establishing and scheduling the strategic objectives of the organization;

- capitalization on the results of the analysis in the general forecasting activity diagnosis on the economic and financial activities of the institution;

- quantification of the estimated disturbing factors and their significance in influencing the evolution of economic and financial situation of the institution;

- elaborating, based on this data, the development strategy of the institution;

- elaborating scenarios in order to establish the tactics through which the organization achieves its strategic objectives;

- establishing priorities and deadlines.

\section{Economic and financial organization}

Economic and financial organization is the role of economic and financial management that defines control, authority and responsibility and includes the necessary activities for the achievement of economic and financial objectives of the institution, their assignement as tasks for the employees and departments and their positioning within a well-defined frame of decision adopting and monitoring.

In order to achieve this role, it is important that tasks pertaining to the economic and financial aspect be prioritized on when the organizational units of the 
institution (departments, services, offices, sections) and functional components (positions, jobs) are created: the dimension of the resources employed and the efficiency of their use, the establishment of centers of efficiency and cost.

Within this role each department must establish an adequate economic and financial database that would allow the institution leadership to use economic and financial performance indicators in such a way that they establish a favourable efforteffect ratio during its activity.

Economic and financial organization combines in a rational and harmonious way all the elements for an organization to function normally: material resources, work and financial resources, etc. at the level of workplaces, departments and the whole organization, assuring the use of material and human potential at its optimal level (Cornescu, Mihăilescu \& Stanciu, 2008).

From this point of view, there are two organizational structures within organizations:

- organizational units with another basic role that cary out activities of an economic and financial nature additionally (departments, sections, offices);

- organizational units with roles of an economic and financial nature: the economic and financial department, accounting department, public auditing, etc.

Specialists emphasize the fact that organization shouldn't be an activity for itself but rather add to the increase of activity, efficicency and lucrative nature of the organization.

A careful approach of this role in public institutions recalibrates the whole concept of their structural and functional organization within a frame of lucrativity and foolproof success.

\section{Economic and financial coordination}

The role of economic and financial coordination includes all the activities through which the adopted decisions and actions of personnel and subunits are correlated within the strategy, tactical procedures and organizational system.

In a perspective, coordination is the organization in motion of the public institution.

The role of economic and financial coordination includes a series of multiple and complex activities divided into two groups:

- bilateral coordination activities;

- multilateral coordination activities, that include the most complex and comprehensive activities with profound influences in all aspects of the activity of the organization.

The quality of the coordination is directly determined by the quality of communication which is influenced in its turn by the quality of overall management.

The results of coordination can be traced, as stimulative or restrictive factors, depending on their quality, in the level of organization flexibility and adaptability, the stimulation and capitalization on the creative potential and initiative of the people.

It would be optimal that the role of coordination and, implicitly, communication within the economic and financial domain be traceable and controlable through feedback as the main buliding block within the economic and financial communication system, as it is indispensable to the management process.

\section{Economic and financial training}

Economic and financial training includes all the activities through which the personnel of the organization is determined to carry out objectives established in the forecasting phase within the established conditions of efficiency.

The motivation of personnel represents a support for training which can be obtained through combining personnel interests with those of the organization, manifest in two ways: positive motivation which derives from the accepted correspondence between the results of the 
activity and personal advantages and negative motivation imposed by threat and reduction of personal advantages in case assumed objectives are not fulfilled.

Obviously, the personal advantages that constitute positive motivation refer to the economic and financial field as a sourse of satisfaction and also as finality. The balanced dynamics of economic and financial factors, the long-term evolution of economic and financial indicators constitute essential arguments for university management in its attempts to motivate personnel in the acheivement of institutional objectives.

\section{Evaluation and monitoring of the} way economic and financial objectives are achieved

Economic and financial evaluation and monitoring are the last stage of the managerial process and they quantify the way in which the other roles of management have been achieved. Through comparing the results with the established objectives the deviations and causes that have generated them are identified, the qualities and weaknesses of the institution are established, and measures are imposed in order to correct and avoid future disfunctions.

A professional approach of economic and financial monitoring is extremely important, which must be created, structured and exercised in an environment of autonomy, democracy and decentralization of decision-making.

We emphasize the very important aspect of evaluation and monitoring being undertaken within the process economic and financial operations in every of its three forms: proactive, simultaneous and post-action.

Information on the results of the organization through effective monitoring is an essential prerequisite for efficient management.

This depends on the capacity of the organization to identify operatively, preactively even, with the changes that occur, on its ability to adapt its roles and activities of conception, personnel, accountancy in accordance with these changes. Such objectives cannot be achieved without an efficient monitoring.

Public institution accountancy cannot be merely a source for data and information based on records: provisional balance and other modern methods must be part of the instruments used by accountancy departments in universities.

In the present conditions, the economic and financial role cannot be limited to procurement of funds; it must play an active (in many cases), decisive role in the way funds are allocated and used, and the planning of ways, methods and procedures are used to obtain the expected result.

\section{Personal reflections}

Economic and financial management represents a segment of general management, an extension of it into the economic and financial area of the organization with the following roles:

- economic and financial forecasting is part of the general forecasting activity of the organization with a particularly significant role, far from being a mere additional component;

- economic and financial organization must fulfill an active role in the organizational activities of the institution;

- economic and financial communication includes conveying messages regarding expenses;

- economic and financial monitoring represents the basis of all other roles of the managerial process.

Depending on the level of the manager withing the economic and financial structure, he/she will apply the roles of management more or less frequently and will use the various roles to a greater or lesser extent within his/her activities.

Consequently, organization and monitoring are most of the time handled superficially. 
On the other hand, as a result of the fact that lower level managers have responsibilities that are only related to planning activities in their own departments, that haven't been prescribed by top management, they channel their main efforts toward the role of organization of departments and work positions as well as monitoring documents of an economic and financial nature.

The coordination of the activities within the economic and financial department is undertaken by higher level managers who have the authority and responsibility to take the most important decisions in this domain.

The organization of tasks and activities in the economic and financial field is a daily activity carried out mainly by lower level management since high level management is responsible of decisions that pertain to the whole institution.

The case of economic and financial monitoring is similar. Even if this role requires a constant process, the activities pertaining to it are distributed to lower level managers that carry out daily monitoring within departments and top management who monitor important documents and the way activities are completed by lower management.

Training is achieved on all levels of management, and, even if it is a more frequent activity of lower level management, high level management training has more significant impact on personnel.

Forecasting cannot be achieved without knowledge of organization structure, the departments' implication into task fulfillment and the abilities of those responsible of the training and achievement of economic and financial objectives.

The organization must take into account the objectives that have been established through planning and creation of the necessary facilities in such a way that monitoring can be efficiently and correctly completed.

The coordination of operations is completed in a way that allows all of the other roles to fulfill requirements and monitoring is carried out over all of the activities executed within the department, including the method of application of management roles.

\section{REFERENCES}

Cornescu, V., Mihăilescu, I., \& Stanciu, S. (2003). Management of organization, Bucharest: All Beck Publishing House.

Niculescu, O., \& Verboncu, I. (1999). Management, Bucureşti: Editura Economică.

Robbins, S, \& Coulter, M. (2007). Management, Upper Saddle River: Pearson. 